\title{
Energy savings evaluation for dry-cooler equipped plants in shopping mall buildings
}

\author{
Alessandra De Angelis*, Luca Ceccotti, Onorio Saro \\ University of Udine, Polytechnic Department of Engineering and Architecture, via delle scienze \\ 208, Udine, Italy
}

Email: alessandra.deangelis@uniud.it

\begin{abstract}
In the present paper the possible energy savings achievable by means of dry coolers adoption in cooling plants serving shopping mall buildings has been carried out.

In these buildings, could happens that, due to internal gains caused by occupancy, lighting, and electrical devices, or because of solar radiation entering through the large skylights on the aisle, some zones have to be cooled also during the middle and the winter seasons.

The aim of this work is the evaluation of the energy saving, reachable when a water indirect free cooling system is integrated into a traditional cooling equipment in a shopping mall. Depending on outside climate conditions, the dry-cooler units could be used alternatively to cool down the refrigerant flow, or the water supplied to fan coils, achieving in such a way an indirect free cooling; so, the proposed system allows to turn off the chiller. By means of energy simulations, electrical energy saving in different locations has been evaluated. Simulations results allowed a comparison between a traditional plant and a plant equipped with a dry-cooler. These simulations were useful to evaluate the influence of weather conditions in the dry cooler integration convenience.
\end{abstract}

Keywords: Trnsys, Energy Saving, Cooling, Commercial Mall, Dry Cooler.

\section{INTRODUCTION}

The cooling energy requirements are certainly a key issue in warm climates. Large increases in building energy consumption are found in the summer, especially during the daytime, while decreases are found in the winter [1].

These aspects are most relevant in buildings which have high volume and high internal thermal loads and a kind of buildings that have these features are the shopping malls. In these buildings, could happens that, in order to preserve the thermal comfort conditions, some zones have to be cooled also during the middle and the winter seasons.

Energy consumption in commercial buildings accounted for $31 \%$ of U.S. primary energy consumption in 2010 [2] and it is increasing directly influenced by climate change.

In fact, due to internal gains caused by occupancy, lighting, and electrical devices, or because of solar radiation entering through the large skylights on the aisle, internal gains could be higher than heat losses through building envelope. Under these conditions, the cooling installation has to be activated during the middle and the winter seasons too.

Vapour compression refrigeration systems involve high energy consumptions and environmental emissions and that makes this kind of technology unattractive. Improving the existing HVAC system is a possible way to reduce energy consumptions of energivorous buildings. Several studies about energy saving strategies regarding the HVAC systems improvement, have been carried out by different authors.

Many of them proposed to add to a traditional refrigeration equipment an evaporative cooling system.

Vakiloroaya et al. in a recent review paper [3] investigated the ability of different approaches to improve the efficiency of HVAC systems in order to obtain an HVAC energy saving. They proposed a hybrid evaporative cooling system in order to reduce the air temperature more than wet-bulb temperature of the outside air, that represents the lowest temperature DEC system can reach.

Results were compared with measured data of an existing central cooling plan of a commercial building and showed that the proposed system allows an energy saving potential up to $52 \%[4]$.

Other authors [5] studied the energy saving obtained combining a central cooling plant with a regenerative evaporative cooling system and they found that this solution is able to accomplish $15.69 \%$ annual electricity saving of the building.

Moreover Heidarnejad et al. [6] evaluated the effectiveness of a hybrid system composed by a nocturnal radiative cooling, a cooling coil and a direct evaporative cooling. Results showed that energy saving obtained with the hybrid system is 
considerably higher than stand-alone direct evaporative cooling.

A combined experimental plant consisting of an IEC unit and a packaged unit air conditioner was realized and tested by Delfani et al. [7]; they found a reduction in cooling load up to $75 \%$ and a reduction in electrical energy consumption around $55 \%$ during cooling season.

Previous studies [8], carried out by the same authors, have evaluated the possible energy savings achievable by means of dry coolers adoption in heating and cooling plants serving office buildings.

The aim of this work is the evaluation of the energy saving in a shopping mall, reachable when a water indirect free cooling system is integrated in a traditional cooling equipment. The indirect free cooling system is achieved by means a dry cooler.

Depending on outside climate conditions, the dry-cooler units could be used alternatively to cool down the refrigerant flow, or the water supplied to fan coils, achieving an indirect free cooling. Under suitable weather conditions, the proposed system allows to turn off the chiller, and this results in electricity saving.

A typical shopping mall has been modeled by means of a building energy performance simulation program (TRNSYS). In this way, cooling and heating demands have been evaluated. The simulations have been carried out using weather data corresponding to northern, central and southern European cities.

Regarding the installation modeling, the technical characteristics of commercial components have been used.

By means of energy simulations, the number of hours in which the chiller could be turned off has been evaluated. Then, simulations for the traditional plant without the dry-cooler, have been carried out for each one of the considered locations, in order to evaluate the electrical energy required by the installation with and without dry-cooler. These simulations were useful to evaluate the influence of weather conditions in the dry cooler integration convenience.

\section{BUILDING MODEL}

A rectangular double floor building with a gross floor area of $20000 \mathrm{~m}^{2}$ and a height of $4 \mathrm{~m}$ were considered. The total volume is $160000 \mathrm{~m}^{3}$. Fig. 1 -a shows the internal layout of a building floor.

The longer edge of building is oriented along north-south axis and the entrance glass doors are on two shorter edges.

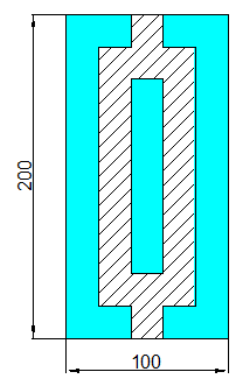

(a)

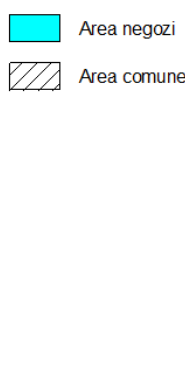

(b)

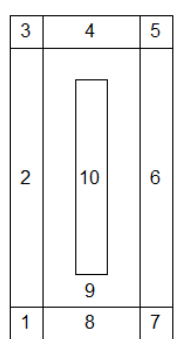

Figure 1. Floor plan for the simulated building with using destination (a), and thermal zones (b)
With reference to internal layout, shops take up perimetral and core zones and occupy $60 \%$ of the total floor area, leaving $40 \%$ of the floor area to a common zone in order to allow a suitable space for the flow of people during the peak time.

Initially, it has been modeled horizontal skylights, but in this way gains of solar radiation were very high; so, a shed roof with 12 vertical skylights, $0.70 \times 2.5 \mathrm{~m}$, has been chosen.

Taking into account the relevant dimension of building, different thermal zones, that have the same internal load and the same heat losses through wall, were set. For each floor different zones, perimeter zones and one core zone, summarized in Fig. 1-b, were considered.

In this way it is possible to predict the thermal performance of any thermal zone in the building and the total building thermal performance is defined according to an assessment related to its thermal zones.

The model of the building, shown in Fig. 2, was created with TRNBuild module.

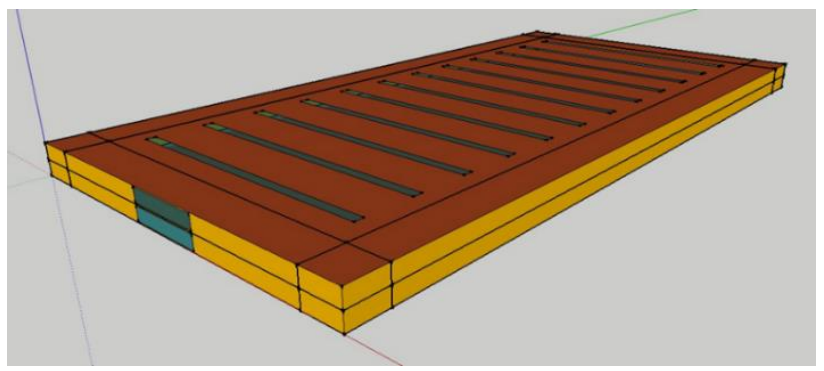

Figure 2. Sketch of the simulated commercial mall

Two different walls and two different slabs were defined:

- external wall

- inner wall

- ground floor

- middle floor

- external ceiling

The building elements properties were summarized in Table 1

Table 1. Building elements construction details

\begin{tabular}{ll}
\hline $\begin{array}{ll}\text { Exterior wall } \\
\text { Material }\end{array}$ & Thickness [m] \\
\hline concrete & 0.07 \\
\hline polystyrene & 0.08 \\
\hline concrete & 0.07 \\
\hline $\mathrm{U}$ & $0.351 \mathrm{~W} / \mathrm{m}^{2} \mathrm{~K}$ \\
\hline \multicolumn{2}{l}{} \\
\hline $\begin{array}{l}\text { Ground floor } \\
\text { Material }\end{array}$ & Thickness [m] \\
\hline tiles & 0.01 \\
\hline concrete & 0.04 \\
\hline polystyrene & 0.08 \\
\hline concrete & 0.3 \\
\hline $\mathrm{U}$ & $0.34 \mathrm{~W} / \mathrm{m}^{2} \mathrm{~K}$ \\
\hline
\end{tabular}

\begin{tabular}{ll}
\hline $\begin{array}{l}\text { Inner wall } \\
\text { Material }\end{array}$ & Thickness [m] \\
\hline concrete & 0.07 \\
\hline polystyrene & 0.06 \\
\hline concrete & 0.07 \\
\hline $\mathrm{U}$ & $0.456 \mathrm{~W} / \mathrm{m}^{2} \mathrm{~K}$ \\
\hline & \\
\hline $\begin{array}{l}\text { Roof } \\
\text { Material }\end{array}$ & Thickness $[\mathrm{m}]$ \\
\hline concrete & 0.1 \\
\hline polystyrene & 0.1 \\
\hline concrete & 0.1 \\
\hline & \\
\hline $\mathrm{U}$ & $0.283 \mathrm{~W} / \mathrm{m}^{2} \mathrm{~K}$ \\
\hline
\end{tabular}

The window glazing value $U_{w}$ was assumed to be 5,8 $\mathrm{W} / \mathrm{m}^{2} \mathrm{~K}$.

Daily and hourly schedules were adopted to control the infiltration, occupation, internal gains and HVAC system. In commercial malls the main internal loads are those due to people and lights, therefore it is very important to know opening times and people turnout. 
In order to carry out more realistic simulations, existing shopping malls with their opening times were considered. Shopping malls, listed in Table 2, are located at the same places chosen for the simulations.

Table 2. Opening times of existing shopping malls

\begin{tabular}{|c|c|c|c|}
\hline City & Days & Opening times & Name \\
\hline Milan & $\begin{array}{l}\text { Mon-Sat } \\
\text { Sun }\end{array}$ & $\begin{array}{l}8.30-21.00 \\
9.00-20.00\end{array}$ & $\begin{array}{l}\text { Centro commerciale } \\
\text { piazza Lodi }\end{array}$ \\
\hline Messina & $\begin{array}{l}\text { Mon-Sat } \\
\text { Sun }\end{array}$ & $\begin{array}{c}9-20.30 \\
9.30-20.30\end{array}$ & $\begin{array}{c}\text { Centro commerciale } \\
\text { Tremestieri }\end{array}$ \\
\hline Udine & $\begin{array}{l}\text { Mon-Thu } \\
\text { Fri }\end{array}$ & $\begin{array}{c}9.30-20.30 \\
9.30-22\end{array}$ & $\begin{array}{l}\text { Centro commerciale } \\
\text { Città Fiera }\end{array}$ \\
\hline Paris & $\begin{array}{c}\text { Mon-Sat } \\
\text { Sun }\end{array}$ & $\begin{array}{c}10.00-20.00 \\
\text { Closed }\end{array}$ & Italie Deux \\
\hline Berlin & Mon-Sun & $9.00-21.00$ & Bikini Berlin \\
\hline Hamburg & $\begin{array}{l}\text { Mon-Sat } \\
\text { Sun }\end{array}$ & $\begin{array}{c}10.00-20.00 \\
\text { Closed }\end{array}$ & Europa passage \\
\hline Geneva & $\begin{array}{c}\text { Mon-Sat } \\
\text { Sun }\end{array}$ & $\begin{array}{c}9.00-19.00 \\
\text { Closed }\end{array}$ & Le Praille \\
\hline Vienna & $\begin{array}{c}\text { Mon-Sat } \\
\text { Sun }\end{array}$ & $\begin{array}{c}9.00-20.00 \\
\text { Closed } \\
\end{array}$ & Wien Mitte \\
\hline Warsaw & Mon-Sun & $10.00-21.00$ & Wola Park \\
\hline Madrid & $\begin{array}{l}\text { Mon-Sat } \\
\text { Sun }\end{array}$ & $\begin{array}{c}10.00-21.00 \\
\text { Closed }\end{array}$ & ABC Serrano \\
\hline
\end{tabular}

The evaluation of electrical equipment loads was carried out according to ASHRAE Standard guidelines (Table 3) and, assuming a low load, it has been considered a value of 30 $\mathrm{W} / \mathrm{m}^{2}$ thinking of a shop inside a shopping mall has a higher electrical load than a single shop.

Table 3. Electrical loads - Ashrae

\begin{tabular}{cccc}
\hline Building & $\begin{array}{c}\text { Low } \\
\text { load } \\
{\left[\mathrm{W} / \mathrm{m}^{2}\right]}\end{array}$ & $\begin{array}{c}\text { Medium } \\
\text { load } \\
{\left[\mathrm{W} / \mathrm{m}^{2}\right]}\end{array}$ & $\begin{array}{c}\text { High } \\
\text { load } \\
{\left[\mathrm{W} / \mathrm{m}^{2}\right]}\end{array}$ \\
\hline Commercial malls & 32 & 54 & 97 \\
\hline Commercial malls (single floor) & 38 & 65 & 67 \\
\hline Shops & 11 & 22 & 43 \\
\hline Restaurant, dining rooms & 16 & 18 & 22 \\
\hline
\end{tabular}

Electrical load was split in a radiative part (30\%) and a convective part $(70 \%)$.

Thermal load of electrical equipment were calculated as product of electrical power, interval time and a coefficient depending on the day of the week; the coefficient was set to 1 during opening hours and to 0,2 during closing hours in order to account for stand-by conditions.

On zones where there are skylights, windows or entrance doors, a infiltration rate equal to $0,5 \mathrm{ACH}$ (Air Changes per Hour) was imposed.

The definition of the number of people inside shopping mall was carried out according to UNI10339-2014 and, for each building, a design value of crowding index equal to 0,2 person $/ \mathrm{m}^{2}$ was considered both sale zone and common zone. The peak value was scaled down based on daily and weekly schedule of occupant's presence.

The fraction of the design value is defined as the ratio of the actual load to the peak or maximum load.
Human sensible and latent heat loads from people depend on their activity and, with reference to ISO7730, assuming a light activity for shopping mall, a load of $185 \mathrm{~W}$ for each person (90 sensible and 95 latent) was chosen.

\section{COOLING PLANT SYSTEM}

The cooling plant system consists of fan coil units fed with water coming from an air conditioning system based on mechanical vapor compression. This air conditioning system needs a significant amounts of electricity. The most widely used refrigeration plant for commercial building is a watercooled condensers system, which often uses recirculation water from cooling towers.

In these systems, water leaves the water-cooled condenser and enters the top of the cooling tower, where it is sprayed over the fills and cooled to a lower temperature by means of evaporation. Thereafter it is supplied to the water-cooled condenser again.

A choice, investigated in present paper, is substituting cooling towers for dry-coolers, which have the advantage of occupying less space and of being more flexible. Moreover, when the weather conditions are suitable, water cooled by drycoolers can be directly supplied to fan-coils, without using the chiller. A schematic layout of the refrigerant equipment is shown in Fig. 3.
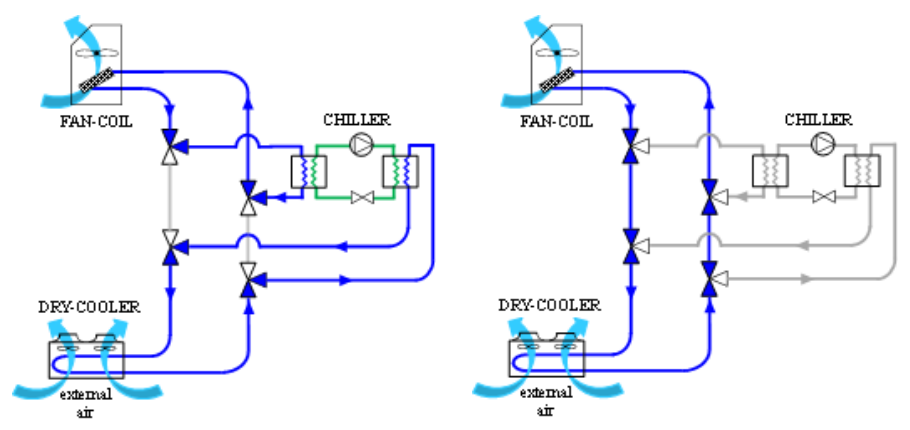

Figure 3. Schematic layout of the refrigerant equipment

\section{SIMULATIONS}

\subsection{Trnsys model}

Dynamic simulation of commercial mall using three different cooling plant configurations is carried out in TRNSYS software on hourly basis.

After drawing the 3D model of the building by means of TRNSYS3D, a plug-in of Sketchup software, and defining internal characteristics and conditions of building in TRNBUILD, all the components of cooling plant are modeled in TRNSYS Studio to run the simulations for three different systems:

- cooling plant with a vapor compression system

- cooling plant with a vapor compression system combined with an indirect free cooling system (working all day long); the cooling plant can works with a traditional mode or with a free cooling mode if the external weather conditions are suitable 
- cooling plant with a vapor compression system combined with an indirect free cooling system (working from 7 am to $11 \mathrm{pm}$ )

TRNSYS performs cooling load calculations with transfer function method by using weather and building information data. Simulations were carried out using an ideal air conditioning system, assuming set points for cooling and heating 24 and $20^{\circ} \mathrm{C}$ respectively.

The TRNSYS model has been implemented using the following type:

- $\quad$ Building (Type 56)

- Weather data (Type 15-3)

- $\quad$ Fan coil (Type 600)

- Chiller (Type 666)

- Dry Cooler (Type 511)

Different climatic conditions are investigated considering ten European cities (Fig. 4):

- Hamburg (Germany)

- Geneva (Switerland)

- Madrid (Spain)

- Messina (Italy)

- Milan (Italy)

- Munich (Germany)

- Paris (France)

- Prague (Czech Republic)

- Warsaw (Poland)

- Wienn (Austria)

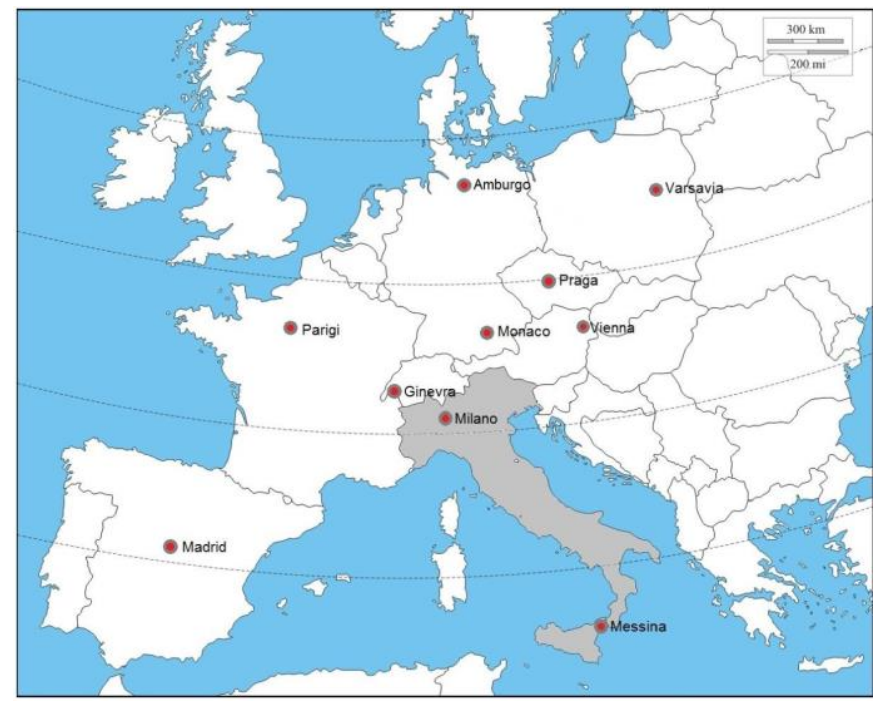

Figure 4. European cities considered in simulations

In order to choose cities with different weather conditions, the Cooling Degree-Hours, Base $\vartheta_{0}\left(\mathrm{CDH}_{-} \vartheta_{0}\right)$, has been considered as discriminating factor; the index is proposed by ASHRAE [9] and is defined as:

$C D H_{-} \vartheta_{0}=\sum_{j=1}^{N}\left(\vartheta_{e}-\vartheta_{0}\right)$ for $\vartheta_{e}-\vartheta_{0}>0$

where $\vartheta_{e}$ is the hourly dry bulb temperature, $\mathrm{N}$ is the number of hours for entire year and $\vartheta_{0}$ is the base temperature.

According to the design value of the internal air temperature, suggested by International Standards [10] for the summer period, a base temperature equal to $26^{\circ} \mathrm{C}$ has been used to evaluate the parameter $C D H$ 26. Fig. 5 shows the CDH_26 for the different cities considered.

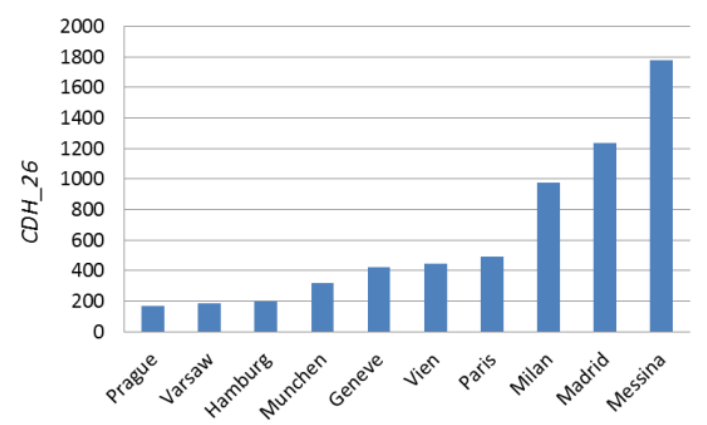

Figure 5. CDH_26 for the different cities considered

\subsection{Chiller performance}

The chiller has been considered as a high performance centrifugal compressor chiller with condenser cooled by water. It has been modeled by means of TRNSYS Type 666 , which allows to take into account the influence of external climatic conditions over the chiller performance. Figure 6 shows the variation of EER values for different chilled water temperatures, varying the cooling water temperature.

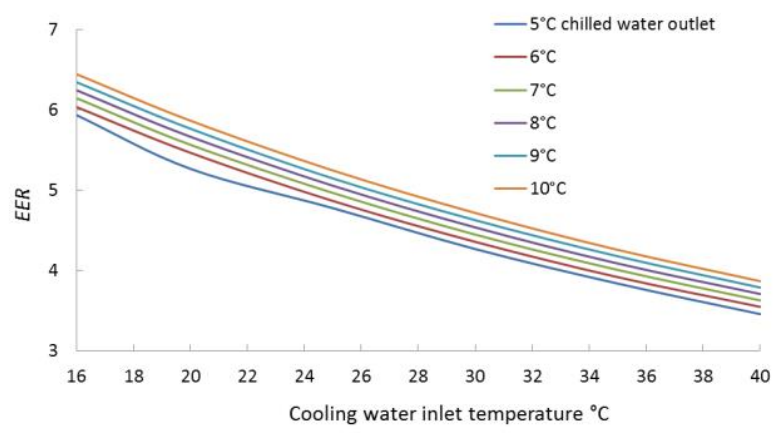

Figure 6. EER trend over cooling water inlet temperature for different outlet temperatures of the chilled water

\subsection{Free cooling}

Cooling plant have to work in free cooling mode only under suitable conditions, that are:

- temperature gradient between internal air and external air have to be greater than $10 \mathrm{~K}$;

- fan-coils have to be switched on.

In particular the first condition takes into account that water have to pass through two heat exchangers and therefore the temperature difference have to be greater than $10 \mathrm{~K}$.

\section{SIMULATION RESULTS}

As it is reasonable to expect, during the winter the cooling plant works mainly in free cooling mode, whereas during the summer the plant works mainly in traditional mode, but the amount of free cooling hours depends on the weather conditions and therefore on the locations.

In fig. 7 it is shown a comparison of the chiller working hours $\mathrm{H}_{\mathrm{C}}$ in two different situations, when the cooling plant doesn't employ free-cooling and when the cooling plant works in a free-cooling mode. 


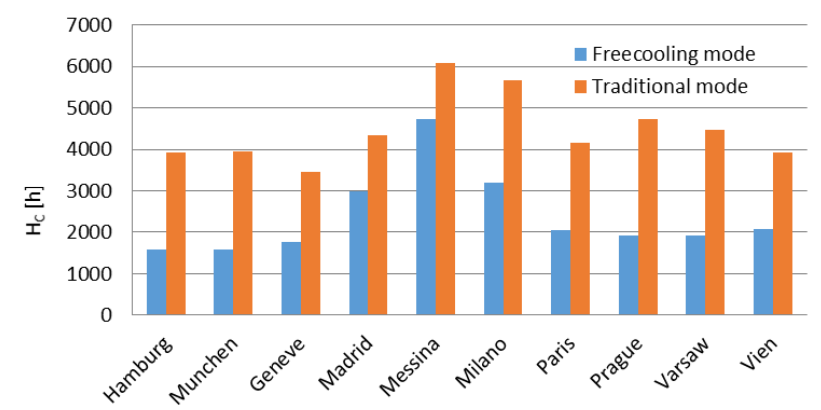

Figure 7. Comparison of the chiller working hours $\mathrm{HC}$ in two different situations, in free cooling mode and in traditional mode

Obviously, the reduction of working chiller hours could not be a meaningful parameter to evaluate benefit of employing free-cooling and for this reason the energy consumptions of two scenarios are considered.

The energy consumptions has been evaluated in both cases, with and without free-cooling mode, and in figure 8 the reduction of electrical energy in percentage for all considered locations is summarized.

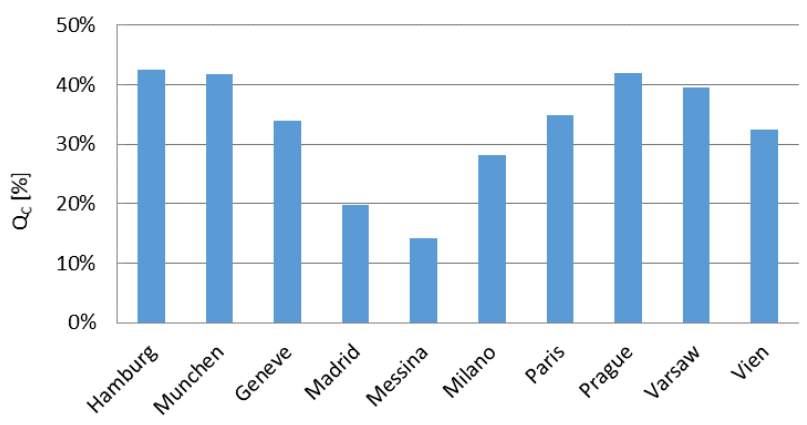

Figure 8. Reduction in percentage of electrical energy consumptions for the considered locations

Above all, as shown in fig. 8 , in some cities the amount of the electrical energy saving is quite considerable due to suitable climatic conditions despite the good performance of the considered chiller.

Also in hot cities, the energy saving percentage reaches significant values as in Messina.

In order to highlight the influence of weather conditions on the amount of energy saving, fig. 9 shows the percentage reduction of the chiller electrical energy consumptions vs CDH 26.

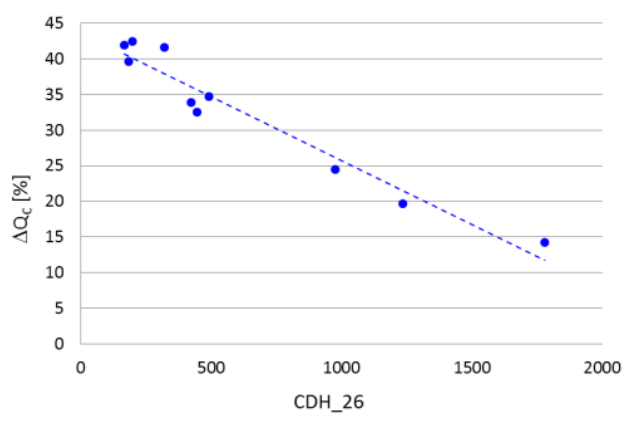

Figure 9. Percentage reduction of the chiller electrical energy consumptions vs $\mathrm{CDH} 26$ for the considered locations
Energy saving shows a good linear dependence with the cooling degrees, leading an index correlation equal to $r=0,95$.

\section{CONCLUSIONS}

In the present study have been investigated the advantages, in terms of energy saving, achievable by means of the integration of an indirect free cooling system in a traditional cooling plant used for a shopping center cooling.

In particular, the dry-cooler units could be used alternatively to cool down the refrigerant flow, or the water supplied to fan coils, achieving in such a way an indirect free cooling. Under suitable weather conditions, the proposed system allows to turn off the chiller and allows to save electrical energy.

A commercial mall with both a dry-cooler equipped cooling plant and a traditional one has been simulated by means of TRNSYS, and the results have been compared in terms of number of hours in which the chiller could be turned off and amount of energy saving. Different weather data (northern, central and southern European cities) have been considered for the simulations.

Simulations show that among the considered locations the city with the greatest annual energy saving amount (42.4\%) is Hamburg, whereas the city with the lowest annual energy saving amount $(14.2 \%)$ is Messina. As it is reasonable to expect, in cities with a colder climate there is a greater energy saving due to a lower value of the external mean air temperature; for the same reason, during the winter the proposed system is more useful.

Further investigations will be carried out taking in to account different thermal characteristics of the building envelope; a more insulated building requires a lower cooling load, which can be more likely supplied employing the external air. Moreover, it will consider the latent heat that have to be disposed of.

\section{REFERENCES}

[1] Huang J., Gurney K.R. (2016). The variation of climate change impact on building energy consumption to building type and spatiotemporal scale, Energy, Vol. 111, pp. 137-153. DOI: 10.1016/j.energy.2016.05.118

[2] Kelso J. (2011). Buildings Energy Data Book Energy, from http://buildingsdatabook.eren.doe.gov/

[3] Vakiloroaya V., Samali B., Fakhar A., Pishghadam K. (2014). A review of different strategies for HVAC energy saving, Energy Conversion and Management, Vol. 77, pp. 738-754. DOI: 10.1016/j.enconman.2013.10.023

[4] Vakiloroaya V., Khatibi M., Ha Q.P., Samali B. (2011). New integrated hybrid evaporative cooling system for HVAC energy efficiency improvement, IEEE/SICE International Symposium on System Integration, Kyoto, Japan, pp. 591-596. DOI: 10.1109/SII.2011.6147546

[5] Khandelwal A., Talukdar P., Jain S. (2011). Energy savings in a building using regenerative evaporative cooling, Energy Build, Vol. 43, pp. 581-591. DOI: 10.1016/j.enbuild.2010.10.026

[6] Heidarnejad G., Farahani M.F., Delfani S. (2010). Investigation of a hybrid system of nocturnal radiative cooling and direct evaporative cooling, Building and 
Environment, Vol. 45, pp. 1521-1528. DOI: 10.1016/j.buildenv.2010.01.003

[7] Delfani S., Esmaeelian J., Pasdarshahri H., Karami M. (2010). Energy saving potential of an indirect evaporative cooler as a pre-cooling unit for mechanical cooling systems in Iran, Energy and Buildings, Vol. 42, pp. 2169-2176. DOI: 10.1016/j.enbuild.2010.07.009

[8] De Angelis A., Ceccotti L., Saro O. (2016). Cooling energy savings with dry-cooler equipped plants in office buildings, International Journal of Heat and Technology, Vol. 34, Special Issue 2, pp. S205-S211. DOI: $\underline{10.18280 / \text { ijht. } 34 \text { S203 }}$

[9] 2009 ASHRAE Handbook of Fundamentals (SI).

[10] ISO 7730 Ergonomics of the thermal environment Analytical determination and interpretation of thermal comfort using calculation of the PMV and PPD indices and local thermal comfort criteria, 2005.

NOMENCLATURE

EER

$\mathrm{H}$

$\mathrm{U}$

$\vartheta$

\section{Subscripts}

$\mathrm{c}$

C

e

W

out energy efficiency ratio number of hours, $\mathrm{h}$ thermal transmittance, W. $\mathrm{m}^{-2} \cdot \mathrm{K}^{-1}$ temperature

chilled

chiller

external

window

outlet 